\title{
Review of the Current Implementation Procedures for the Self Help Service Center Management System
}

by

Jeffrey G. Kirby

Jeffrey D. Moll

Kurt A. Larson

The Self Help Service Center Management System (SHSCMS) is a personal computer (PC)-based system that automates the recordkeeping at an installation's Self Help Store and supports the use of bar coding. This system provides inventory control and reorder, costing to account and quarters, and rates of consumption and store utilization. Development of this product has continued since SHSCMS was first used successfully in 1989 by Army installation Directorates of Engineering and Housing (DEHs). Since 1993, the number of new users has grown rapidly, and a review of the current implementation process should determine if it is the most efficient manner to transition new users to full competence in the least possible time and with the lowest level of frustration.

\section{For Reference}

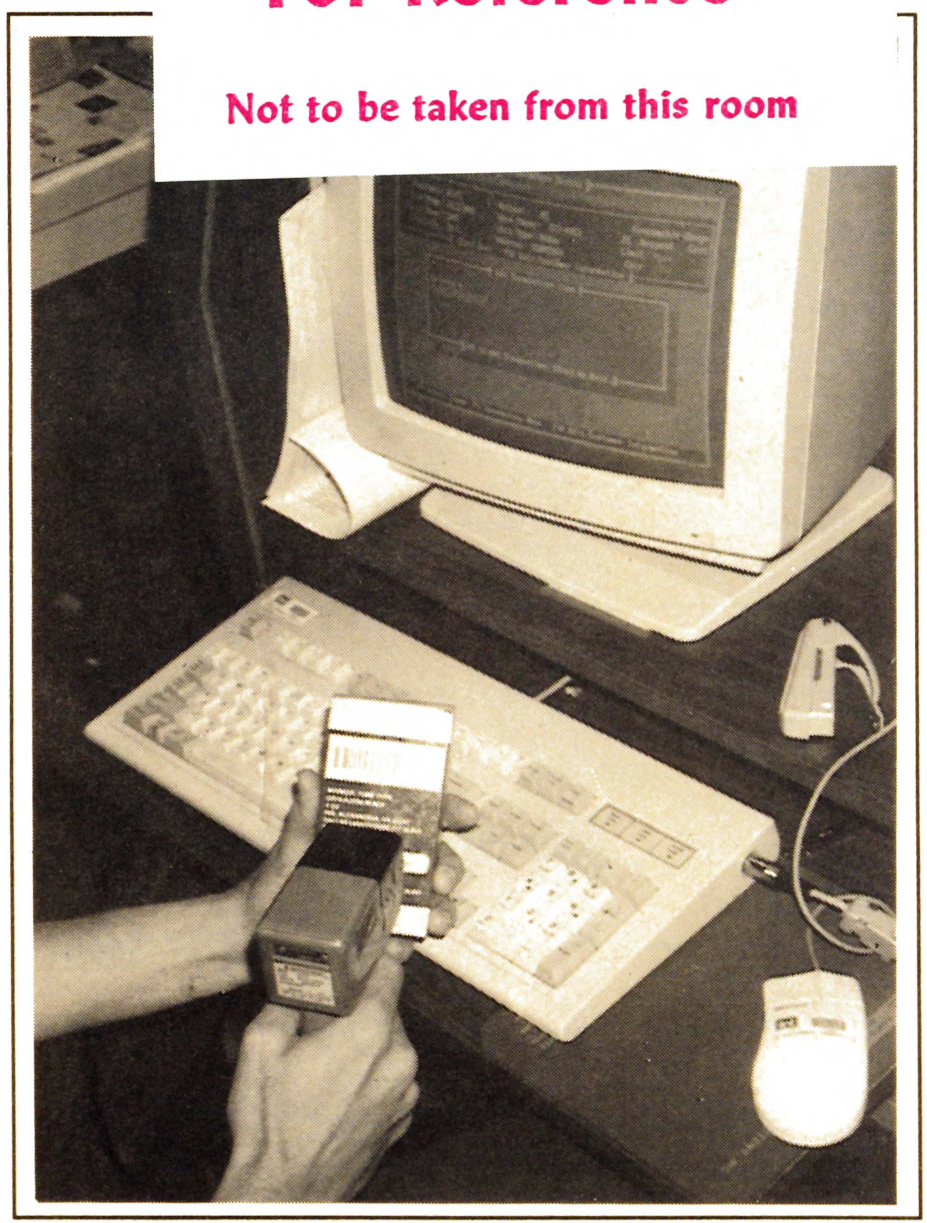


The contents of this report are not to be used for advertising, publication or promotional purposes. Citation of trade names does not constitute ar. official endorsement or approval of the use of such commercial products. The findings of this report are not to be construed as an official Department of the Army position, unless so designated by other authorized documents. 


\section{USER EVALUATION OF REPORT}

REFERENCE: USACERL Technical Report 96/80, Review of the Current Implementation Procedures for the Self Help Service Center Management System

Please take a few minutes to answer the questions below, tear out this sheet, and return it to USACERL. As user of this report, your customer comments will provide USACERL with information essential for improving future reports.

1. Does this report satisfy a need? (Comment on purpose, related project, or other area of interest for which report will be used.)

2. How, specifically, is the report being used? (Information source, design data or procedure, management procedure, source of ideas, etc.)

3. Has the information in this report led to any quantitative savings as far as manhours/contract dollars saved, operating costs avoided, efficiencies achieved, etc.? If so, please elaborate.

4. What is your evaluation of this report in the following areas?

a. Presentation:

b. Completeness:

c. Easy to Understand:

d. Easy to Implement:

e. Adequate Reference Material:

f. Relates to Area of Interest:

g. Did the report meet your expectations?

h. Does the report raise unanswered questions? 
i. General Comments. (Indicate what you think should be changed to make this report and future reports of this type more responsive to your needs, more usable, improve readability, etc.)

5. If you would like to be contacted by the personnel who prepared this report to raise specific questions or discuss the topic, please fill in the following information.

Name:

Telephone Number:

Organization Address:

6. Please mail the completed form to:

Department of the Army

CONSTRUCTION ENGINEERING RESEARCH LABORATORIES

ATTN: CECER-TR-I

P.O. Box 9005

Champaign, IL 61826-9005 


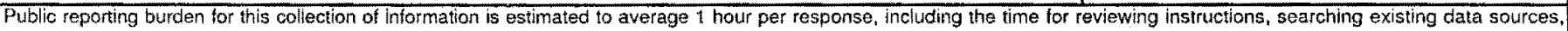

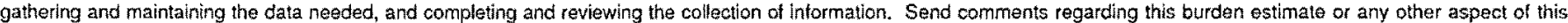

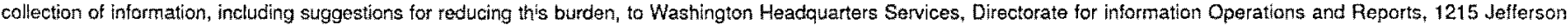
Davis Highway, Sulte 1204, Arington, VA 22202-4302, and to the Ofice of Managament and Budget, Paperwork Reduction Project (0704.0188), Washington, DC 20503.

\begin{tabular}{l|l|l} 
1. AGENCY USE ONLY (Leave Blank) & 2. REPORT DATE REPORT TYPE AND DATES COVERED
\end{tabular}

\begin{tabular}{l|l|l|} 
& August 1996 & Final \\
\hline
\end{tabular}

Review of the Current Implementation Procedures for the Self Help Service Center Management System

6. AUTHOR(S)

Jeffrey G. Kirby, Jeffrey D. Moll, and Kurt A. Larson

7. PERFORMING ORGANIZATION NAME(S) AND ADDRESS(ES)

U.S. Army Construction Engineering Research Laboratories (USACERL)

P.O. Box 9005

Champaign, IL 61826-9005

5. FUNDING NUMBERS

MIPR

$\mathrm{E} 87950431$

9. SPONSORING / MONITORING AGENCY NAME(S) AND ADDRESS(ES)

U.S. Army Center for Public Works (USACPW)

ATTN: CECPW-EB

7701 Telegraph Road

Alexandria, VA $22315-3862$

\section{SUPPLEMENTARY NOTES}

Copies are available from the National Technical Information Service, 5285 Port Royal Road, Springfield, VA 22161.

12a. DISTRIBUTION I AVALABILITY STATEMENT

12b. DISTRIBUTION CODE

Approved for public release; distribution is unlimited.

13. ABSTRACT (Maximum 200 words)

The Self Help Service Center Management System (SHSCMS) is a personal computer (PC)-based system that automates the recordkeeping at an installation's Self Help Store and supports the use of bar coding. This system provides inventory control and reorder, costing to account and quarters, and rates of consumption and store utilization. Development of this product has continued since SHSCMS was first used successfully in 1989 by Army installation Directorates of Engineering and Housing (DEHs). Since 1993, the number of new users has grown rapidly, and a review of the current implementation process should determine if it is the most efficient manner to transition new users to full competence in the least possible time and with the lowest level of frustration.

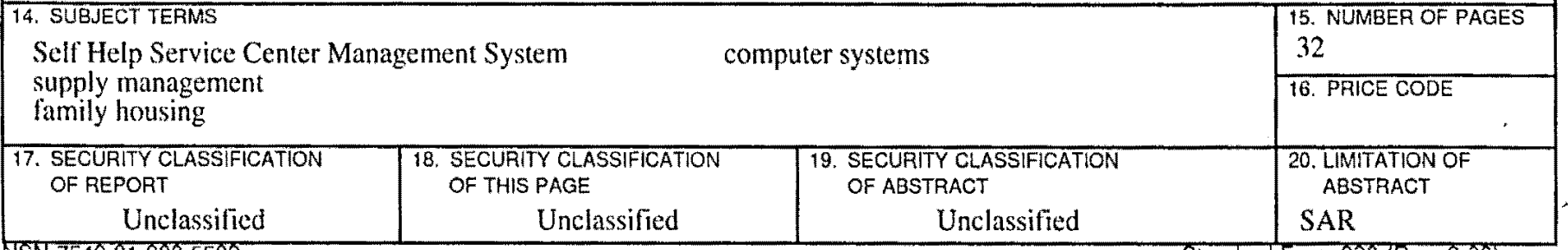




\section{Foreword}

This study was conducted for the U.S. Army Center for Public Works (USACPW) under Military Interdepartmental Purchase Request (MIPR) No. E87950431 dated September 1995, entitled "Self Help Service Center." The technical monitor was Jim Routson, CECPW-EB.

The work was performed by the Engineering Processes Division (PL-E) of the Planning and Management Laboratory (PL), U.S. Army Construction Engineering Research Laboratories (USACERL). The USACERL principal investigator was Jeffrey G. Kirby. Dr. Michael P. Case is Chief, CECER-PL-E and L. Michael Golish is Operations Chief, CECER-PL. The USACERL technical editor was Linda L. Wheatley, Technical Information Team.

COL James T. Scott is Commander of USACERL and Dr. Michael J. O'Connor is Director. 


\section{Contents}

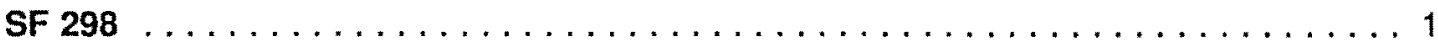

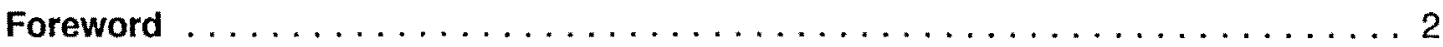

List of Tables $\ldots \ldots \ldots \ldots \ldots \ldots \ldots \ldots \ldots \ldots \ldots \ldots \ldots \ldots \ldots$

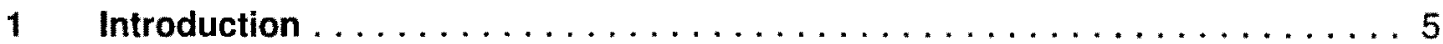

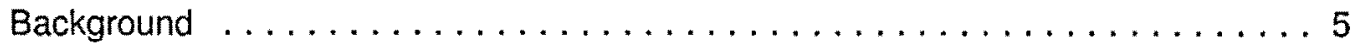

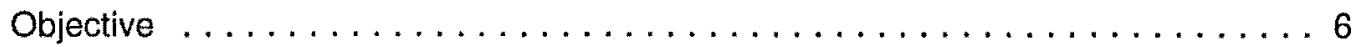

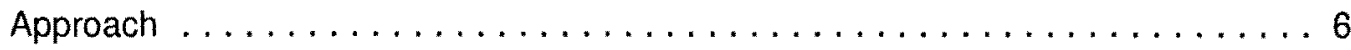

Mode of Technology Transfer $\ldots \ldots \ldots \ldots \ldots \ldots \ldots \ldots \ldots \ldots \ldots \ldots$

2 Review of the Current Delivery Process $\ldots \ldots \ldots \ldots \ldots \ldots \ldots \ldots$

Current Implementation Process $\ldots \ldots \ldots \ldots \ldots \ldots \ldots \ldots \ldots \ldots \ldots \ldots$

Current Follow-up Support Procedures $\ldots \ldots \ldots \ldots \ldots \ldots \ldots \ldots \ldots$

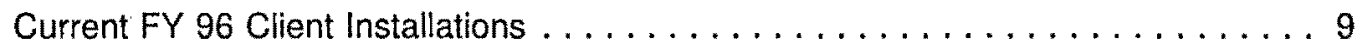

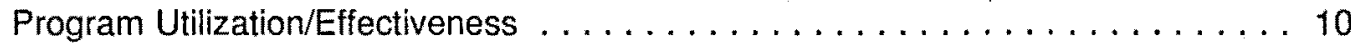

3 Identified Improvements to the Implementation Process $\ldots \ldots \ldots \ldots \ldots \ldots$

Need for An Implementation Manual $\ldots \ldots \ldots \ldots \ldots \ldots \ldots \ldots \ldots \ldots \ldots$

Survey of Informal Needs of Sites Using SHSCMS . . . . . . . . . . . 13

Survey of SHSCMS Features Being Used $\ldots \ldots \ldots \ldots \ldots \ldots \ldots \ldots \ldots$

Survey of Recent SHSCMS Adopters . . . . . . . . . . . . . . . 18

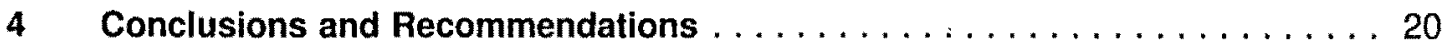

Meeting User Desired Implementation Informational Needs $\ldots \ldots \ldots \ldots \ldots \ldots$

Use of Success Measures . . . . . . . . . . . . . . . . . . . . 20

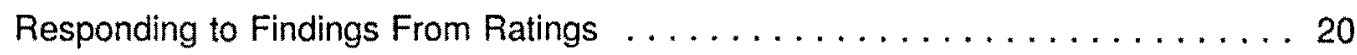

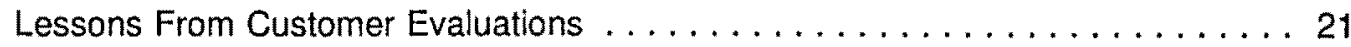

Appendix A: Self Help Service Center Management System Utilization

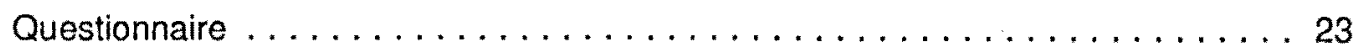

Appendix B: Questionnaire for the Reported Benefits and Hindrances to the

Concept of Self Help . . . . . . . . . . . . . . . . . . . . 28

\section{Distribution}




\section{List of Tables}

Tables

$1 \quad$ Client installations for SHSCMS (FY 96) $\ldots \ldots \ldots \ldots \ldots \ldots$

2 Current use of Self Help Stores by client installations $\ldots \ldots \ldots \ldots \ldots 11$

$3 \quad$ Estimate of dollar utilization of Self Help Stores per visit $\ldots \ldots \ldots 11$

4 Self Help installation program comparison factors $\ldots \ldots \ldots \ldots \ldots 11$

$5 \quad$ User information requested for system $\ldots \ldots \ldots \ldots \ldots \ldots \ldots$

$6 \quad$ User information requested for start-up $\ldots \ldots \ldots \ldots \ldots \ldots \ldots$

$7 \quad$ User information requested for daily operation $\ldots \ldots \ldots \ldots \ldots \ldots$

8 Evaluation of SHSCMS program feature utilization $\ldots \ldots \ldots \ldots 16$

$9 \quad$ Implementation assessment for new users $\ldots \ldots \ldots \ldots \ldots \ldots$

10 SHSCMS Program feature use analysis $\ldots \ldots \ldots \ldots \ldots \ldots \ldots$ 


\section{Introduction}

\section{Background}

Most DOD installations have some form of Self Help so that occupants of troop and family housing may make limited maintenance, repair, and improvements to their living quarters. The Self Help Store provides material, instruction, and loan equipment for this program. The Self Help Service Center Management System (SHSCMS) is a personal computer (PC) barcode-based system that automates the recordkeeping at a Self Help Store. This system includes inventory control and reorder, costing to account and quarters, and rates of consumption and store utilization. Development of this system has continued since SHSCMS was first used successfully in 1989 by Army installation Directorates of Engineering and Housing (DEHs). Version 3.0 was recently released.

Until the end of fiscal year (FY) 1994, the SHSCMS customer base was fairly constant, with only one or two new clients per year. During this period, the program was extensively upgraded in response to suggestions from the existing customers. During FY 94-95, the customer base grew 45 percent, and in the first half of FY 96, the growth was 52 percent. This dramatic growth in the number of new requests for SHSCMS implementation indicates that the program is meeting the needs of a wide number of installations. Key to meeting the customer need for this program is a rapid and successful implementation.

Additionally, the U.S. Army Construction Engineering Research Laboratories (USACERL) and Resource Center Enterprises, Inc. (RCE) have tried to provide a comprehensive support network for SHSCMS users. This support includes a software users manual", direct dial-up support, weekly status inquiry calls, an electronic bulletin board, and an annual users group meeting.

* Self-Help Service Center Management System User's Manual (Resource Center Enterprises, Inc., Urbana, IL, February 1996). 


\section{Objective}

The objective of this work was to review the current implementation process and determine if it is the most efficient manner to transition new users to full competence in the least possible time and with the lowest level of frustration on the part of the user.

\section{Approach}

Assessment of the effectiveness of current implementation was divided into several complementary tasks. First, all sites using SHSCMS were surveyed by telephone to determine what topics should be included in an implementation manual and the relative importance of each topic. Second, a mail survey (Appendix A) was conducted to identify to what extent current features of the program were being used. The survey population consisted of any site that had been using the program for longer than 6 months. In addition, the mail survey collected several data elements that could be used to develop performance measures to identify any differences between users. Finally, recently implemented SHSCMS sites were asked for their views on the strengths and weaknesses of the current implementation process.

Once the above data were collected, researchers compared what users suggested the implementation manual should contain with what program features "mature" users accessed. These findings were reviewed and combined with recent clients' opinions of the positive and negative aspects of the existing implementation process.

\section{Mode of Technology Transfer}

The conclusions reached from this effort and reported in this document will be used in two ways. First, where appropriate, identified topics will be included within an implementation manual. Second, procedural findings will be incorporated within the implementation practices used for all new-client program deliveries.

A third method of technology transfer will be to incorporate the generalizable findings into other software and technology delivery methods. Suggestions and recommended methods will be distributed to other system developers at USACERL and through published professional journals. 


\section{Review of the Current Delivery Process}

\section{Current Implementation Process}

The method for delivery of SHSCMS has evolved over the past 3 years. From 1989 to 1991, USACERL was centrally funded for the development of the program. Many copies of the program diskettes and manuals were distributed free of charge (approximately 100 copies each of Versions 1.0, 1.1, 2.0, and 2.1) to any interested party. If a client had a problem, they could call for technical support, but neither USACERL nor RCE followed up with these customers after the initial mailing. During this period, limited records were kept of who received these programs although earlier versions were apparently quite useful and dependable. Even in FY 96, some clients with earlier versions are still requesting upgrades. Other clients are totally new starts (or ones with some type of home-grown system). The approach followed with both types of client is similar except that more time is normally spent with new clients than with those who are upgrading from earlier versions. 'The 10-Step Implementation Process is defined below:

1. The installation makes initial contact with the USACERL Point of Contact (POC).

2. USACERL sends a proposal with a descriptive package that includes a demonstration diskette and order information.

3. The acquiring installation reviews the information and discusses any unique requirements with USACERL and the support contractor (RCE).

4. If the decision is to purchase, the installation sends a MIPR, signed proposal, and Federal Information Processing (FIP) form to USACERL to initiate the purchase process.

5. USACERL awards a contract to the support contractor.

6. RCE makes initial contact to determine what kind of Automated Data Processing (ADP) equipment will be used at the site (i.e., PCS, printers, barcode devices, and network) and any existing database system currently being used.

7. RCE purchases and mails a modem and a copy of PC AnyWhere to the site. RCE converts any existing database for utilization with SHSCMS and mails a users manual to the site.

\footnotetext{
* PC AnyWhere is manufactured by Symantec Corp., 505 B San Marin Drive, Novato, CA 94947. The program allows the Self-Help support contractor to "dial into" a client's PC and correct problems.
} 
8. RCE assists by telephone, as necessary, with the installation of PC AnyWhere, the modem, and makes suggestions for networks settings required to support SHSCMS.

9. RCE dials up the installation PC and installs the current SHSCMS version and any modified databases. Operational questions are answered at this time.

10. During the first several weeks, numerous telephone calls typically are made by both RCE and the site to resolve start-up issues. Once these issues are resolved and for the remainder of the contract, RCE calls weekly to check status (if no other calls have occurred during that week).

\section{Current Follow-up Support Procedures}

\section{Direct Dial-up}

The above procedures are intended to provide the adopting installation with a fairly high level of support initiated by RCE. Direct dial-up was initiated in 1994 and has provided the using site with prompt response and resolution of problems that occur while in an operational mode. Before direct dial-up, floppy diskettes often had to be mailed back and forth. This approach was unacceptable as it left the site "down" for an extended period of time. By using PC AnyWhere, RCE can dial up the client machine and directly assess the problem. RCE can either solve the problem or provide specific instructions to the local system administrator.

\section{Fault Logging}

All releases of Version 3.0 have an error log program to capture program activities occurring before a system crash or error. This error log helps the support programmer to better understand what may have caused the system problem. Before Version 3.0, determining the fault cause was often difficult because keyboard entries were not captured and operators often could not remember exactly what happened before the problem occurred.

\section{Weekly Query Call}

Each funded support site is contacted by RCE at least once a week to provide information and determine the system status. If RCE has been contacted by the site during the week, that conversation suffices. If no contact has been made and telephone attempts have been unsuccessful, a telefax is sent (e.g., to an overseas site with a working hours shift). 


\section{Bulletin Board Support}

For their clients' use, RCE maintains an electronic bulletin board with four support areas provided: Personal E-mail, General Public Messages, Let's Improve Self Help, and Bugs and Fixes. The main menu also provides information on the current software version and allows users to download the program to update their systems. Some sites use this feature extensively; however, most do not.

\section{Users Group Guidance}

Each year a Self Help Users Group meeting is held at one of the client installations. The first two meetings, held in FY 93 and FY 94, were 1-day meetings that focused on existing problems and what enhancements were desired. In addition, the attendees jointly prioritized the problems needing correction and additional features needed. By FY 95, the program had been totally rewritten and significant functionality had been added. It had also been noted during the earlier users group meetings that some longtime users were not as familiar with the program as was believed, so it was decided that the new version could not be delivered without some form of training. Therefore, the FY 95 users group meeting was expanded to train users on the new version or features of the current version as well as to discuss the existing system problems and desired enhancements. To provide the additional "hands on" training, the meeting was expanded to $21 / 2$ days. The FY 95 meeting attendees responded favorably to the addition of the training. The success of the meeting also highlighted that the delivery of a users manual is not sufficient to achieve adequate technology transfer.

\section{Current FY 96 Client Installations}

The Self Help user base has grown rapidly without any strong advertisement campaign. In FY 93, an effort to totally fund Self Help by customer funding was begun with 11 installations. By year-end FY 95, the client base had grown to 21 installations. The renewal rate has been consistently high for the annual support package (excluding base closures, renewals between FY 93 and FY 94 were 82 percent; renewals between FY 94 and FY 95 were 94 percent with a 45 percent customer account growth during that period). During the first half of FY 96, the client support count had risen 52 percent to 32 installations. Two Navy installations are now supported as well as seven Army installations in Germany and one in Korea.

Most major installations in Forces Command (FORSCOM) and the U.S. Army Training and Doctrine Command (TRADOC) are now using the program. Table 1 lists the 32 FY 96 client installations. 
Table 1. Client installations for SHSCMS (FY 96).

\begin{tabular}{|lc|}
\hline FORSCOM & MDW \\
Fort Campbell & Fort Meade \\
Fort Drum & USAREUA \\
Fort Hood & 100 th ASG(Germany) \\
Fort Lewis & 104 th ASG (Germany 6 sites) \\
Fort Polk & USARPAC \\
Fort Riley & Fort Greely \\
TRADOC & Fort Richardson \\
Fort Benning & Fort Wainwright \\
Fort Eustis & 19th TAAC (34th Support Group) \\
Fort Leavenworth & 104 ASG(Korea) \\
Fort Lee & Corps of Engineers \\
Fort McCellan & USACERL Warehouse \\
Fort Rucker & CEHND Warehouse \\
Fort Sill & Navy Family Housing San Diego \\
Granite City Depot & NAWS China Lake \\
Fort Monmouth & \\
Redstone Arsenal & \\
AMC* & \\
*AMC - U.S. Army Materiel Command; MDW - U.S. Army Military District of Washington; & \\
USAREUR - U.S. Army Europe; USARPAC - U.S. Army Pacific; TAAC - Theater Area Army \\
Command; CEHND - U.S. Army Engineer Division, Huntsville; NAWS - Naval Air Weapons \\
Station.
\end{tabular}

\section{Program Utilization/Effectiveness}

Any assessment of the success of a software product's implementation requires the development of an evaluation scale that includes more than a "good" or "bad" subjective assessment by the client. Since SHSCMS has been cooperatively molded by the users for the last 3 years, a good measure of the success of this management tool is the degree to which all program features are used within each of the categories: system settings, procedural issues, inventory issues, and report utilization. This evaluation scale must not be indiscriminately applied, as not all features are equally important to effective store operation nor are they all required. Use of a majority of the features in each category can substantiate a loosely defined successful implementation. External factors such as local command interest, resource allocation, and review of the implementation process also influence the success of program implementation. Especially important in this area are funding authorization, manpower allocations, and performance reviews.

In addition to measuring program use within categories, part of a mail survey (Appendix B) to current users of SHSCMS also gathered information that could be used to develop performance parameters. These parameters would allow comparisons between installations. Tables 2 and 3 provide an overview of current program use. The factors have been normalized by the number of accounts so they could be combined 
Table 2. Current use of Self Help Stores by client installations.

\begin{tabular}{|l|c|c|c|}
\hline \multicolumn{1}{|c|}{ Visits/Yr/Account } & Average & Low & High \\
\hline Family Housing Account & 6.37 & 3.50 & 9.92 \\
Barracks Account & 7.74 & 3.39 & 11.78 \\
\hline
\end{tabular}

Table 3. Estimate of dollar utilization of Self Help Stores per visit.

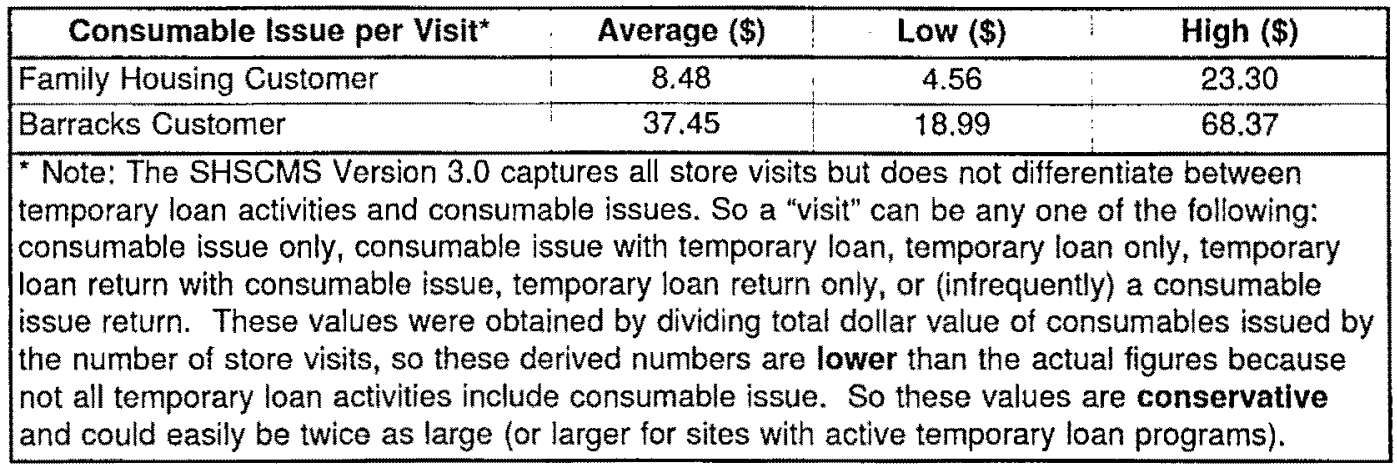

to obtain an average. A range is also provided to indicate the relative differences between installations of varying size and/or the degree of program use.

The non-normalized figures presented in Table 4 identify the overall measures of activity of the sites using SHSCMS. So, while Tables 2 and 3 give an overall perspective of the program independent of installation size and program emphasis, Table 4 is an overview of the size range of the Self Help Programs across the installations responding to the survey.

An FY 95 Army Audit Agency evaluation of the Self Help Program at Fort Benning (report not available) determined a savings to the government of $\$ 2.57$ for each dollar of material issued. Other rough savings estimates from clients (subjective without evaluation) ranged upward from 3:1. So not only does the program improve the quality of life of the military service member, it is also cost effective and yields a considerable payback over the initial material cost. Tables 2 and 4 show the acceptance of the program by the military service member. The typical family housing occupant and

Table 4. Self Help installation program comparison factors.

\begin{tabular}{|lrrrr|}
\hline \multicolumn{1}{|c}{ Store Slze/Activity Factors* } & Average & \multicolumn{1}{c|}{ Low } & \multicolumn{1}{c|}{ High } \\
\hline Number of Store Visits $/ \mathrm{Yr}$ & 24,027 & 6,556 & 64,044 \\
Value of Consumable Items Issued/Yr (\$) & 197,195 & 124,594 & 248,156 \\
Operating Budget/Yr (\$) & 740,000 & 235,000 & $2,000,000$ \\
Amount of Budgeted Cost/Visit (\$) & 45.53 & 8.13 & 158.05 \\
Number of Consumable Items Stocked & 951 & 235 & 2117 \\
\hline "Note: Only one "large" store reported, so these averages are lower than actual. \\
\hline
\end{tabular}


barracks resident visits the store five or six times per year, making automation necessary to provide speedy and accurate recording of the transactions.

\section{Identified Needed Data To Support Performance Analysis}

Attempts to use the existing reporting structure of SHSCMS to develop effective store performance factors identified several data and report shortcomings (specified below) that will be rectified in future program enhancements.

General parameter data. General informational reporting currently missing from SHSCMS includes: total number of accounts, total number of accounts by account type, total number of unique consumable items stocked, total number of types of temporary loan items, total count of temporary loan items, percentage breakdown of temporary loan items between available/issued/out-for-repair, and total consumable inventory value. The ability to develop these data elements is required to support sound store management practices.

Consumable issue by account type. Although the program can identify store visits by type account, it cannot identify consumable issues by account type. The only way to obtain that figure is to run a lengthy report by financial account and add the correctly related accounts by type. Such a report will be added.

Identify temporary loan visits. Currently SHSCMS accumulates any completed transaction process into a single store visit number. As indicated in the detail for Table 3, the Store Utilization recording should be expanded to maintain a secondary record of the total activities that relate only to a temporary loan. 


\section{Identified Improvements to the Implementation Process}

\section{Need for An Implementation Manual}

One recurring observation over the past 3 years was the wide variation in how specific sites used the SHSCMS program. The "normal" procedure of explaining the program and providing a users manual to explain the software functions did not include a rationale for the program's design or how to use the program for maximum effectiveness. Often the eager new user would start using the program and not take the time to consider how the program was to be used. The required careful initial steps to establish financial codes, accounts, customers, and inventory categories were often not made. The long-term ramifications of early decisions that impact program functionality became apparent to users later, typically after considerable data had been loaded into the program. Users do not want to re-enter large amounts of data, so the program functionality is reduced. For this reason, it was decided to develop an implementation manual to complement the users manual. The purpose of the manual would be to explain the program design rationale and present "best practices" suggestions for the user to achieve the most program functionality.

To determine what should be included within the implementation manual, installations using the program were surveyed by telephone to gather their thoughts on what the manual's content should include. Second, a questionnaire was mailed to all installations that had been using the program for more than 6 months. The objective of this questionnaire was to obtain a clear understanding of what program features were being used on a routine basis. Along with the questionnaire, some specific system data were collected to measure store and program utilization.

\section{Survey of Informal Needs of Sites Using SHSCMS}

Before initiating an implementation manual, RCE conducted a survey of what issues the supported sites felt should be included within the manual. A detailed questionnaire (Appendix A) was administered to 20 sites experienced with the SHSCMS program. Questions covered four areas: store parameters, hardware and software configuration, daily operation, and getting started issues. Each site was asked to use 
a Linkart five-point scale (from 1 = very unimportant to. 5 = very important) to rate the relative importance of topics that should be included within the implementation manual. The scores were recorded, the results averaged, and the topic scores then ranked. The results of this questionnaire are being used to both identify the topic content of the implernentation manual and to determine the degree of thoroughness to which the topics are to be covered.

Tables 5, 6, and 7 present the findings from the questionnaire for each of the topic areas. The survey items, with a few exceptions, are closely ranked considering that a five-point rating was used. The possible conclusion is that users have a wide range of automation assistance needs so most items were viewed as important. Another important conclusion is that this type of information, which is not provided by a typical users manual, is desired. The findings presented in Tables 5, 6, and 7 support the hypothesis that information provided in an implementation manual is desired by system users. The two lowest ranked items in Table 5 were for standalone systems (most sites use local area networks) and barcode equipment (only half of the sites use

Table 5. User Information requested for system.

\begin{tabular}{|l|c|}
\hline \multicolumn{1}{|c|}{ Hardware and Software Topics } & Relative Interest \\
\hline Printer recommendations & 4.0 \\
Recommended server for networked workstations & 3.9 \\
Recommended workstation for networks & 3.8 \\
Recommended network software & 3.6 \\
Recommended network interface cards & 3.5 \\
Barcode printers & 3.4 \\
Barcode equipment & 3.3 \\
Recommended hardware for standalone system & 3.1 \\
\hline
\end{tabular}

Table 6. User Information requested for start-up.

\begin{tabular}{|l|c|}
\hline \multicolumn{1}{|c|}{ Topics for Getting Started With Self Help } & Relative Interest \\
\hline Creating customers and accounts & 4.7 \\
Creating and maintaining inventory records & 4.7 \\
Setting temporary loan policies & 4.4 \\
Use of supply/reorder information & 4.2 \\
General features that support inventory management & 4.1 \\
Establishing account limits & 3.8 \\
Lock-out policies for customers & 3.6 \\
Managing detailed facility information & 3.6 \\
Managing repair and loan itoms & 3.5 \\
Counter service vs. open store checkout concepts & 3.5 \\
Setting store hours and holidays & 3.4 \\
Using barcodes in store operations & 3.1 \\
Password assignments/security concepts & 2.6 \\
\hline
\end{tabular}


Table 7. User information requested for daily operation.

\begin{tabular}{|l|c|}
\hline \multicolumn{1}{|c|}{ Topics for the Daily Operation of the Self Help Program } & Relative Interest \\
\hline Data management and backup & 4.8 \\
User training & 4.5 \\
Daily operation procedures & 4.5 \\
System administration & 4.5 \\
Report preparation and effective use & 4.5 \\
Warehouse operation (receipt and reorder) & 4.4 \\
Quick reference materials for use at the checkout terminal & 4.4 \\
Upgrading, bug detection, and enhancement identification & 4.3 \\
Barcode use procedures & 3.4 \\
Use of electronic bulletin board & 3.4 \\
\hline
\end{tabular}

bar coding). The same can be said for the two lowest ranked items in Tables 6 and 7 , which reflect procedures or operations not used by the majority of system users.

\section{Survey of SHSCMS Features Being Used}

A mail questionnaire (Appendix B) was constructed to identify what program features were being used. In addition, the questionnaire measured the degree of implementation of each feature. It is important to note that full utilization of all features is not necessarily "better" than partial use. Each using installation is expected to structure their use of SHSCMS to best meet their needs. Some features, however, should be used by all to gain maximum benefits from this system. Survey responses were used to identify what features of the system should be stressed in the implementation manual and to identify those features not currently being used and therefore considered candidates for removal in future versions of the program. Seven main topic areas were evaluated (see Table 8). The findings were that the original outline for the manual was appropriate. Most sites use the major classes of features of the program. The variation is normally restricted to specific program features. The one major area of variation is the use of bar coding. Since only half the sites use bar coding, items relating to bar coding have a lower level of use than other features. This was also noted in the earlier survey of suggested content for the manual. Table 8 gives the findings related to use of program features by responding installations. Analysis of this use follows the table. 
Table 8. Evaluation of SHSCMS program feature utilization.

\begin{tabular}{|c|c|}
\hline SHSCMS Program Feature Use & Average Value \\
\hline \multicolumn{2}{|l|}{ Global System Settings $(1=$ Yes, $0=$ No $)$} \\
\hline Consumable limits & 1.00 \\
\hline Accounts & 0.86 \\
\hline Customers & 1.00 \\
\hline Environmental Settings $(1=Y$ es, $0=\mathrm{No})$ & 0.86 \\
\hline Default active days & 0.71 \\
\hline Turn in hours after open & 0.86 \\
\hline Print issue receipts & 0.86 \\
\hline Negative balance printout & 0.71 \\
\hline Reprint negative balance & 0.43 \\
\hline Flag when over limit & 0.57 \\
\hline Lockout Codes $(1=$ Yes, $0=\mathrm{No})$ & 0.43 \\
\hline Password Functions $(1=\mathrm{Yes}, 0=\mathrm{No})$ & 0.43 \\
\hline \multicolumn{2}{|l|}{ Procedural Issues $(1=Y e s, 0=\mathrm{No})$} \\
\hline Issue when over limit & 0.86 \\
\hline Issue when loan overdue & 0.29 \\
\hline Access data outside of program & 0.86 \\
\hline Reset limits & 0.86 \\
\hline Purge data & 0.86 \\
\hline Track hazardous materials & 0.43 \\
\hline Use categories for store items & 0.86 \\
\hline Post housing clearance & 0.86 \\
\hline Use store utilization report for store hours & 1,00 \\
\hline Use barcode & 0.43 \\
\hline \multicolumn{2}{|l|}{ Inventory Issues $(1=$ Yes, $0=\mathrm{No})$} \\
\hline Supplier & 0.71 \\
\hline Reorder & 1.00 \\
\hline Item location & 0.57 \\
\hline Order filter & 0.57 \\
\hline Seasonal adjustment & 0.57 \\
\hline UPC mapping to NSN & 0.57 \\
\hline Reorder all needed inventory & 0.86 \\
\hline Receive inventory & 1.00 \\
\hline Order history report & 0.57 \\
\hline Temporary loan items in repair & 0.57 \\
\hline Facility information & 0.71 \\
\hline \multicolumn{2}{|l|}{ Report Utilization ( $2=$ Often, $1=$ Sometime, $0=$ Never) } \\
\hline Consumable usage history & 1.71 \\
\hline Outstanding loans & 1.86 \\
\hline Overdue loan & 2.00 \\
\hline Store utilization & 1.71 \\
\hline Inventory status and check sheets & 1.14 \\
\hline Customer listing & 0.57 \\
\hline Print catalog/labels & 0.57 \\
\hline Print barcode labels & 0.14 \\
\hline Print barcode catalog & 0.29 \\
\hline Inventory on hand & 1.29 \\
\hline Minimum balance & 1.14 \\
\hline
\end{tabular}




\section{Analysis of Current System Use}

Global system settings. All sites except one use the global limit setting of the system. This is encouraging since the accountability of the program depends on establishing limits for what can be drawn from the store.

Environmental settings. These settings establish basic system routines (i.e., default days for temporary loans, when loan items are due after the store is open, how hand receipts are printed, whether negative balances should be shown, whether the operator should be notified when accounts exceed the authorized level of consumable issue). All surveyed installations use some of these features. The least used feature is the reprinting of the negative balance report.

Lockout codes. Lockout codes are used by less than half the sites. Earlier versions of the program did not have this feature, but it was identified as a requirement during a users group meeting. Use of this feature is recommended as an easy method to implement sanctions against customers who abuse the services and products provided by the store.

Password function. Less than half the sites use this function. The Password Function is the only way to provide verifiable controls for the system, so its use is strongly recommended.

Procedural issues. Use of the topics within this section are not mandatory. It is interesting to note that over half the sites continue to issue when the account has exceed the pre-established limit. This policy seems to negate the concept of a limit, and it is recommended that sites that have this policy should review this decision. Less than half the sites use the program to track hazardous material. The program can do this quite easily, and the low use in this area is believed to be more from a lack of understanding of this possibility than from a conscious decision not to track with the program. Fort Drum uses the limit feature to alert store operators that a client has a problem that cannot be solved by self help. For example, if more than six roach traps are issued per quarter, the store issues a work order to the post engineer to solve the infestation problem.

Inventory issues. Three items are used by less than half the users: Order Filter, Temporary Loan Items in Repair, and Seasonal Adjustment. The Order Filter is a review process that determines if an order meets a defined "reasonable size" criteria. These features probably would be used by more sites if the functions were better understood. Temporary Items in Repair adjusts the available inventory down 
(temporarily) until the loan item is returned to service. Cost for repairs are collected, but, at present, the software does not have any reporting features incorporated.

Report utilization. All reports should be used. Few sites, however, use a majority of the available reports. Many of the existing reports were requested during users group meetings, so they should be meeting a defined customer need.

\section{Survey of Recent SHSCMS Adopters}

A telephone survey was conducted of three sites that had recently completed (or were in the process of completing) implementation. A questionnaire was used to ensure the same questions were asked of all respondents. The goal was to analyze the findings and determine general results. The telephone interview would provide another important view of what was necessary for implementation, and these sites could best comment on the actual conversion process because it had occurred recently (within the past 6 months).

The survey covered status of the Self Help Program before acquisition of SHSCMS, the initial set-up process, operational performance of the system, and any questions the site might have.

The scores of answers related to key issues of the implementation process were added and then divided by the total possible score to provide a success implementation score between 0 (not successful) and 1 (totally successful). An overall rating of the average of all newly implemented sites was also calculated.

\section{Findings From the Survey}

Table 9 indicates all sites had some form of Self Help Program before acquiring SHSCMS. Approximately half the sites had some automated tools and about three quarters had or could obtain automation assistance. However, for the initial setup, it appears about half did not feel they were adequately informed about the software installation, database creation/conversion, and the necessary user training. The evaluation of technical support from RCE was lower here than during the post installation period. Operationally, the only significant shortfall was in the existence of appropriate standing operating procedures (SOPs), which is a bit surprising because the stores existed before system acquisition, so SOPs must not have existed then either. 
Table 9. Implementation assessment for new users.

\begin{tabular}{|l|c|}
\hline \multicolumn{1}{|c|}{ Factor } & Average Score \\
\hline (Scoring O=no, 1=yes) & \\
Status Before & 1.00 \\
Prior store & 0.33 \\
Prior automation tools & 0.83 \\
Have PC/network skills or locally available support & \\
& \\
Initial Setup Understanding & 0.67 \\
What was required to implement & 0.67 \\
Hardware requirements & \\
Network requirements & 0.67 \\
Decisions on system parameters or barcoding & 0.67 \\
Software installation & 0.67 \\
Database creation or conversion & 0.33 \\
User training & 0.67 \\
Support from RCE & \\
Operation Evaluation & \\
SHSCMS reliability & 0.67 \\
Network reliability & \\
SHSCMS system administration & 1.00 \\
Network administration & \\
Support from RCE & 0.67 \\
Software meets store needs & 0.83 \\
Appropriate SOPs are in place & 0.33 \\
Overall Total Score (individual scores =0.46, 1.00, and 0.50) & \\
\end{tabular}




\title{
4 Conclusions and Recommendations
}

\author{
Meeting User Desired Implementation Informational Needs
}

The implementation process seems to only partly prepare the new sites for what is required to successfully install and operate SHSCMS. As Table 9 shows, only about half the sites reported they clearly understood what prior parameters needed to be identified before installation. Related issues of software installation, database creation, and user training were also not rated highly by about half the sites. This could account for the lower rated support during the implementation process. Many of these issues will be explained in the proposed implementation manual. In addition, a review of the interactivity between RCE and the start-up client will be conducted.

\section{Use of Success Measures}

Before preparation of this report, no criterion for measuring success of the delivery or use of SHSCMS existed. RCE and USACERL relied upon responses to routine telephone calls and the client's willingness to renew the support agreement the following year as the sole measure of the operation's success. Table 9 findings can be used to evaluate the success of an implementation and provide guidance for improvement. Likewise the success of the system used can be determined for each SHSCMS site by adding the Table 8 scores for each of the features used and dividing by the total possible score. Use of bar coding, although viewed as important, was only weighted by half in these calculations. Effective utilization scores therefore ranged from 0 (totally unsuccessful) to 1 (totally successful). For both of the above, success was viewed as a score of 0.50 or greater. Thus a "performance" factor can be derived and used to assist sites to improve their operations.

\section{Responding to Findings From Ratings}

Taking an analytical approach to reviewing performance allows comparison of both the implementation process and system utilization by mature users. This approach also identifies what should be changed to improve both implementation and system utilization. Table 9 identifies the areas that must be improved during future 
implementations, and Table 10 can be used to develop suggestions to mature users on improving the benefits that can be obtained from SHSCMS.

\section{Lessons From Customer Evaluations}

Before conducting this evaluation, the 10-Step Implementation Process was viewed as more than adequate. Analysis of the findings indicates that, although the process is quite comprehensive, oversights often occur, especially the following.

\section{Unclear Implementation Requirements}

Several sites did not appear to have a clear understanding of what the implementation steps were going to be. The implementation manual is intended to fill this gap. It is recommended that an additional checklist be provided to the site (perhaps with a timeline) to assist with an understanding of what is to come as well as what decisions must be made before system start-up.

\section{Tracking Start-up Progress}

In several cases, the implementation process was flawed and the process stopped. When this occurred it was often left to the client site to notify RCE when they were ready to begin. Although the responsibility to request support rests with the client, the delay was often quite long. The establishment of a timeline with fixed time boundaries is suggested. When this limit is exceeded, notifying the client is suggested as a means to put the implementation schedule back on track.

\section{Review of Operations}

This evaluation has identified some measures of normal store performance and feature utilization. It is suggested that RCE provide normative figures to all clients annually.

Table 10. SHSCMS Program feature use analysis.

\begin{tabular}{|l|c|}
\hline Factor Evaluated & Average Score \\
\hline Total Evaluation (individual scores $=0.58,0.62,0.82,0.47,0.50,0.52,0.32)$ & 0.59 \\
Consumable limits & 0.93 \\
Environmental settings & 0.71 \\
Lockout codes & 0.43 \\
Password functions & 0.43 \\
Procedural issues & 0.73 \\
Inventory issues & 0.70 \\
Report utilization & 0.56 \\
\hline
\end{tabular}


This overview would provide objective performance measures of the Self Help Program at the client site.

\section{Improve Customer Query Skills}

Even though each site was contacted weekly, problems with the system still occurred that were not promptly reported to RCE. In some cases, instead of calling the correct installation POC, RCE called the individual who negotiated the purchase of the support for the installation. This individual was often unfamiliar with the day-to-day operation of the system and might report that the system was "fine" when, in fact, problems existed. In other cases, RCE did not ask specific questions about system performance. Improved survey questions, identification of correct site POCs, and better interpretation of responses should reduce the occurrence of unreported problems or delays in reporting the problems. 


\section{Appendix A: Self Help Service Center Management System Utilization Questionnaire}

Purpose: The intent of this questionnaire is to get a measure of what features of the SHSCMS are currently being used. If you are unsure of any of these items, please consult the users manual. Please answer each question. Information will be summarized, and individual installation responses will not be reported.

\section{System Settings:}

Do you use global settings? __ N _ Y .

If so, please check those used:

- Consumable Limits

_accounts what limit for what period

_customers what limit for what period

_ Environmental Settings

- Default Active Days

- Turn in Hours after Open

- Print Issue Receipts

- Negative Balance Printout

- Reprint Negative balance

_ Flag When Over Limit

_ Lockout Codes (Users Manual, p 13)

_ Password Functions (Users Manual, p 16)

Procedural Issues:

$\mathrm{Y}_{-} \mathrm{N}_{-}$Do you issue when usage limits are exceeded?

$\mathrm{Y} \_\mathrm{N}_{\text {_ }}$ Do you issue when temporary loans are overdue?

Y_N_ Do you access the database outside of Self Help? 
$\mathrm{Y}_{-} \mathrm{N}_{\text {_ }}$ Do you reset the usage limits? If so, when?

$\mathrm{Y} \_\mathrm{N} \_$Do you purge or store old data? If so, when?

$\mathrm{Y} \_\mathrm{N}$ _ Do you use the system to track hazardous materials?

$\mathrm{Y} \_\mathrm{N}$ _ Do you use categories to classify store items?

$\mathrm{Y} \_\mathrm{N}$ _ Does Post Housing require approval from store prior to allowing customers to clear quarters?

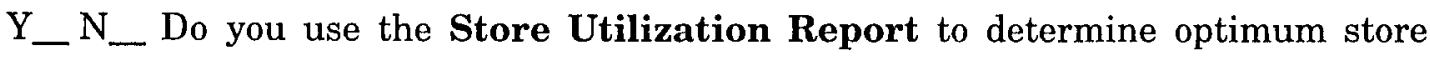
hours?

Y_N_ Do you use bar coding? Only about half our sites use bar coding. Please indicate the benefits if you use bar coding or if you do not use bar coding, why not?

Inventory Issues:

$\mathrm{Y} \_\mathrm{N} \_$Do you use the Supplier Information feature?

Y_

$\mathrm{Y}_{\text {_ }} \mathrm{N}_{\text {_ }}$ Do you use the Item Location feature?

$\mathrm{Y} \_\mathrm{N}$ _ Do you use the Order Filter feature?

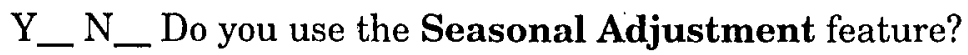

$\mathrm{Y} \_\mathrm{N}$ _ Do you use the mapping of multiple UPC/stock numbers to a single NSN?

Y_ 
$\mathrm{Y} \_\mathrm{N}$ _ Do you use the Receive Inventory feature?

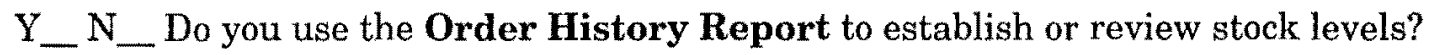

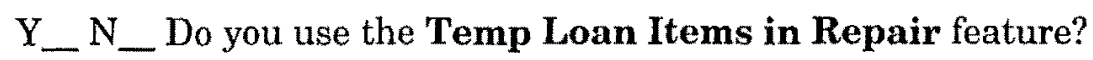

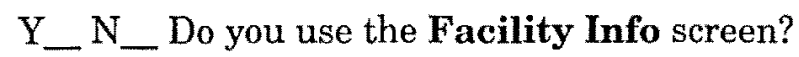

Report Utilization: Please indicate which reports you use by checking the appropriate frequency column.

Often Sometimes Never

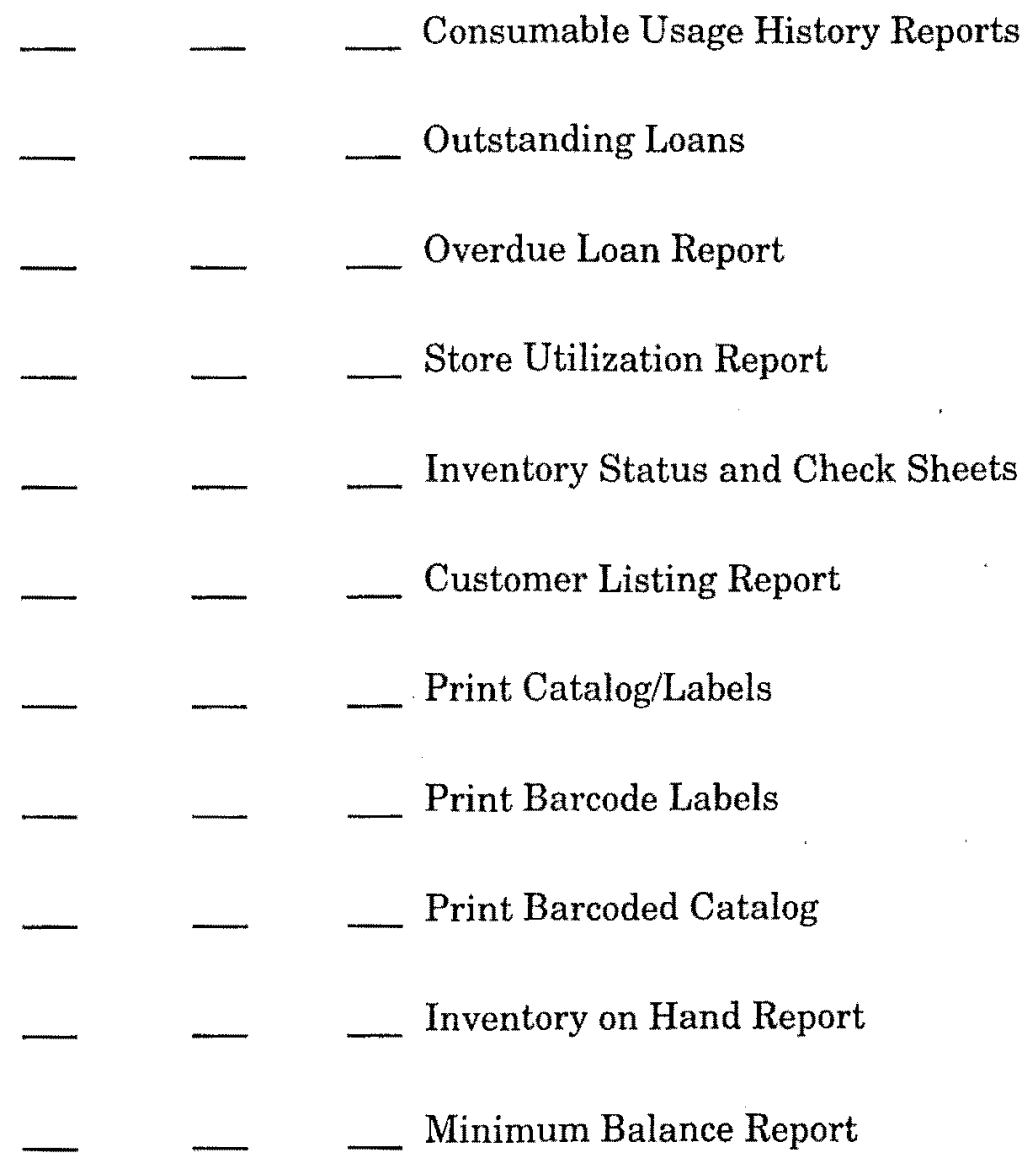


Store Analysis: Please run the following reports and send them with the completed questionnaire. Where possible, set the query period to 1 March 1995 to 29 February 1996.

1. Store Utilization Report

for 1 hour interval (not graphical output but table)

All

Family

Barrack

Other

2. Consumable Usage History

by financial code for all items (summary by $\mathrm{FC}$ )

please also provide: the number of accounts the number of Items stocked the annual store budget

Suggestions for Improvements: Please feel free to enter any suggestions below: 
DA Self Help Questions: Mr. Bryan Nix the DA Self Help Proponent, wants to ask you these questions related to the general Self Help effort (not our program).

1. What are the top two or three benefits from Self Help to the installation?

a.

b.

c.

2. What barriers, if overcome, would make your installation's Self Help effort more successful?

a.

b.

c.

d.

Submitting Site: POC 


\section{Appendix B: Questionnaire for the Reported Benefits and Hindrances to the Concept of Self Help}

What problems did you encounter with your implementation of SHSCMS?

Status Before:

Did you have an existing Self Help Store?

Did you have any automated tools before implementation?

Did you have PC/Network Skills or "local available support"?

\section{Initial Setup}

Understanding of what was required to implement

Hardware

Network

Decisions on System parameters or bar coding use

Software Installation

Database Creation or conversion

User Training

Support from RCE 
Operations

SHSCMS System Reliability

Network Reliability

SHSCMS System Administration

Network Administration

Support from RCE

Software Operation meeting store needs

Having appropriate SOPs in place

\section{Open Comments}




\section{USACERL DISTRIBUTION}

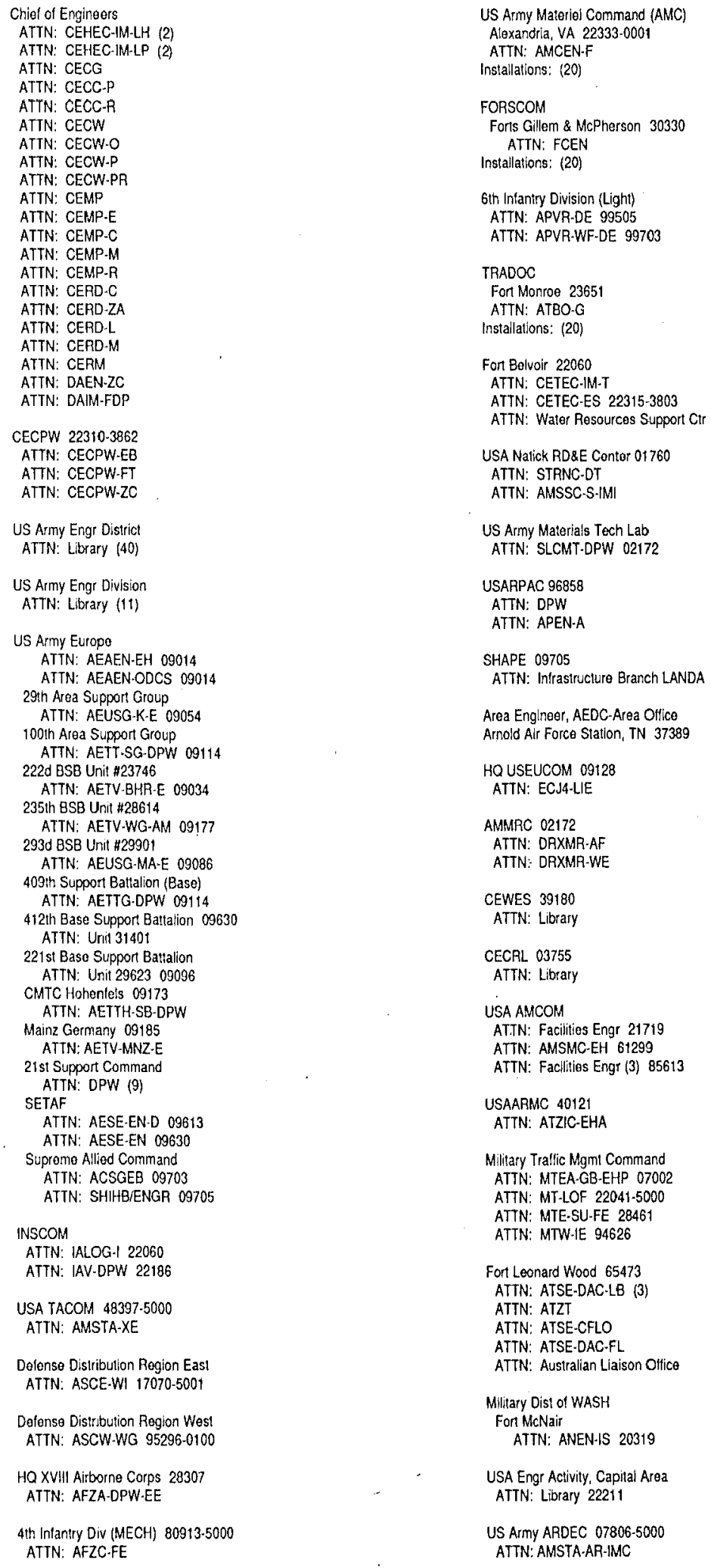

Engr Socioties Library ATTN: Acquisitions 10017

Dofense Nuclear Agency ATTN: NADS 20305

Delense Logistics Agency ATTN: MMDIS 22060-6221

National Guard Bureau 20310 ATTN: NGB-ARI

US Military Academy $1099^{\circ}$ ATTN: MAEN-A ATTN: Facilities Engineer ATTN: Geography \& Envr Engrg

Naval Facilities Engr Command ATTN: Facilties Engr Command (8) ATTN: Division Otfices (t1) ATTN: Public Works Center (8) ATTN: Naval Constr Battalion Cir 93043 ATTN: Naval Facilities Engr Service Center 93043.4328

8th US Army Korea ATTN: DPW (11)

USA Japan (USARJ) ATTN: APAJ-EN-ES 96343 ATTN: HONSHU 96343 ATTN: DPW-Okinawa 96376

416in Engineer Command 60623 ATTN: Gibson USAR CIr

US Army MEDCOM

ATTN: MCFA 78234.6000 Fitzsimons Army Medical Center 80045.5000 ATTN: MCHG-PW

Fort Detrlck 21702-5000

ATTN: MCHS-IS

Fon Sam Houston 78234.5000

ATTN: MCFA-PW

Walter Reed Army Medical Center 20007-5001 ATTN: MCHL.PW

Tyndall AFB 32403

ATTN: HOAFCESACES

ATTN: Engrg \& Swc Lab

USA TSARCOM 63120

ATTN: STSAS-F

Amerlcan Public Works Assoc. 64104-1806

US Army CHPPM

ATTN: MCHB-DE 21010

US Gov't Prining Office 20401

ATTN: Roc Soc/Doposit Sec (2)

Nat'l Institute of Standards \& Tech ATTN: Library 20899

Delense General Supply Center ATTN: DGSC-WI 23297-5000

Delense Construction Supply Center ATTN: DCSC-WI 43216-5000

Deiense Tech Info Center 22060.6218 ATTN: DTIC.O (2) 
DEPARTMENT OF THE ARMY

CONSTRUCTION ENGINEERING RESEARCH LABORATORIES

CORPS OF ENGINEERS

PO BOX 9005

CHAMPAIGN, ILLINOIS 61826-9005

OFFICIAL BUSINESS

BULK RATE

US POSTAGE

$$
\text { PAID }
$$

CHAMPAIGN IL

PERMIT NO. 871 